\title{
INFLUÊNCIA DO HEPES NA MATURAÇÃO IN VITRO DE OÓCITOS CANINOS OBTIDOS DE CADELAS EM DIESTRO E ANESTRO
}

\author{
INFLUENCE OF HEPES ON IN VITRO MATURATION OF CANINE \\ OOCYTES IN DIFFERENT STAGES OF THE ESTROUS CYCLE
}

\author{
Leda Maria Costa Pereira ${ }^{1,2^{*}}$ ORCID http://orcid.org/0000-0001-7973-4063 \\ Paulo Ricardo Oliveira Bersano² ORCID http://orcid.org/0000-0002-3646-3205 \\ Maria Denise Lopes ${ }^{1}$ ORCID http://orcid.org/0000-0002-2540-6299 \\ ${ }^{1}$ Faculdade de Medicina Veterinária e Zootecnia - UNESP, Botucatu, SP, Brasil. \\ 2Universidade Estadual do Ceará, Fortaleza, CE, Brasil. \\ *Autora para correspondência - ledamcp@hotmail.com
}

\section{Resumo}

Diferentemente de outras espécies domésticas, a maturação in vitro (MIV) de oócitos caninos apresenta sucesso limitado. O objetivo deste estudo foi avaliar o efeito do HEPES na maturação in vitro de oócitos caninos obtidos de cadelas em diestro e anestro. Os ovários foram coletados, isolados assepticamente e transportados refrigerados a uma temperatura de $4{ }^{\circ} \mathrm{C}$. Os complexos cumulusoócito (CCOs), provenientes das duas fases do ciclo estral, foram submetidos a dois tratamentos: meio TCM-199 com adição de 25 mM de HEPES (GT) e meio sem suplementação (GC). Depois de 72 horas de maturação, os CCOs foram desnudados, fixados e corados com HOESCHT 33342 para avaliação da maturação nuclear. Os oócitos obtidos da fase de anestro e diestro do GT demonstraram, em relação ao grupo GC, maior frequência de oócitos nos estágios de M-II ( $p<0,01)$. Comparando-se os diferentes status reprodutivos, observou-se que os oócitos obtidos da fase de diestro apresentaram índices maiores de QVG e M-II. Nossos resultados demonstraram que o HEPES preserva a viabilidade e morfologia oocitária, indispensáveis para a aquisição da competência meiótica, potencializando as taxas de M-II, e que os oócitos obtidos da fase de diestro estão mais aptos a completarem a maturação oocitária.

Palavras-chave: meio de cultivo; biotécnicas; ciclo estral; competência meiótica; cadelas.

\begin{abstract}
Unlike other domestic animals, in vitro maturation (IVM) of canine oocytes still has limited success. The aim of this study was to evaluate the effect of HEPES on the in vitro maturation of dog oocytes in anestrus and diestrus. Ovaries were collected, aseptically isolated and transported refrigerated at a temperature of $4^{\circ} \mathrm{C}$. Cumulus-oocyte complexe (COCs) from the two phases of estrous cycle were subjected to two treatments: medium TCM-199 with addition of $25 \mathrm{mM}$ HEPES (TG) and medium without supplementation (CG). After $72 \mathrm{~h}$ of maturation, COCs were denuded, fixed and stained with Hoechst 33342 to assess nuclear maturation. The oocytes obtained from the anestrus and diestrus phases of the TG showed a higher frequency of oocytes in metaphase II (M-II) $(p<0.01)$ stage.Comparing the different reproductive status, it was observed that the oocytes obtained from the diestrus phase presented higher rates of GVBD (germinal vesicle breakdown) and M-II. Our results showed that HEPES preserves the viability and oocyte morphology essential for the acquisition of meiotic competence, increasing the M-II rates and that the oocytes obtained from the diestrus phase
\end{abstract}


are better able to complete oocyte maturation.

Keywords: culture medium, biotechniques, estrous cycle, meiotic competence, bitches.

Recebido em: 28 de junho de 2018

Aceito em: 5 de junho de 2019

\section{Introdução}

A maturação in vitro (MIV) é uma etapa crucial para a produção in vitro (PIV) de embriões em diversas espécies. De acordo com Byskov et al. ${ }^{(1)}$, ao ser removido do ambiente folicular, o complexo cumulus-oócito (CCO) perde seu contato com as células foliculares e, devido à interrupção da transferência de fatores que inibem a quebra da vesícula germinativa (QVG), a meiose é reiniciada. Em cães domésticos, independente das condições de cultivo adotadas, a parcela de oócitos que permanecem no estágio de vesícula germinativa $(\mathrm{VG})$ é alta. Os resultados não são promissores, apresentando índices de 0 a $58 \%$ para retomada da meiose e em média $20 \%$ para metáfase II (M-II) ${ }^{(2-}$

4) Na Medicina Veterinária, a MIV pode oferecer diferentes alternativas para preservar a fertilidade e diversidade genética de indivíduos de alto valor genético que falharam em se reproduzir naturalmente ou precisaram submeter-se a ovário-histerectomia devido a razões médicas e para a preservação de espécies ameaçadas de extinção ${ }^{(5)}$.

A maioria dos meios utilizados na espécie canina é adaptada de protocolos padronizados para outras espécies, como bovinos e suínos, não considerando as particularidades reprodutivas da cadela. Desta forma, a elaboração de um meio de cultivo específico para canídeos é de suma importância para preservar a viabilidade e a morfologia oocitária, indispensáveis para a aquisição da competência meiótica $^{(6)}$. Em cadelas, os meios mais utilizados para a MIV são o SOF (Synthetic Oviduct Fluid) ${ }^{(7)}$ e principalmente o TCM-199 (Tissue Culture Medium 199) ${ }^{(8)}$, suplementados com proteínas, hormônios, antioxidantes e fatores de crescimento. O meio TCM-199 tamponado com HEPES [N(2-hydroxyethyl)-piperazine-N'-(2-ethanesulphonic acid)] é usado comumente como meio de preservação $^{(9)}$, transporte de oócitos ${ }^{(10)}$, assim como para a lavagem dos $\operatorname{CCOs}^{(11)}$. Entretanto, em outras espécies, o HEPES vem sendo empregado, com resultados eficazes, no cultivo de embriões em bovinos ${ }^{(12)}$, coelhos ${ }^{(13)}$ e suínos $^{(14)}$. De acordo com Vajta et al. ${ }^{(15)}$, um fator preponderante para alcançar bons resultados na PIV de embriões, com relação à quantidade e qualidade de embriões, é a menor amplitude de variação do $\mathrm{pH}$ dos meios. A variação do $\mathrm{pH}$ está associada com a retomada da meiose e alterações podem influenciar no potencial de desenvolvimento oocitário. Nesse cenário, o HEPES é utilizado como tampão para evitar essas alterações nos meios de maturação e cultivo embrionário $^{(10)}$.

Apesar de várias pesquisas ${ }^{(13-14)}$ utilizarem o HEPES no sistema de PIV de embriões de diferentes espécies, não há estudos sobre os efeitos desse meio na MIV de oócitos caninos. O objetivo deste estudo foi avaliar o efeito do meio TCM-199 tamponado com HEPES na MIV de oócitos caninos obtidos da fase de diestro e anestro. Nós hipotetizamos que o meio HEPES, por ter um $\mathrm{pH}$ diferenciado dos meios utilizados rotineiramente na MIV de oócitos caninos, pode proporcionar melhores índices de metáfase I e II nessa espécie.

\section{Material e métodos}

Os ovários utilizados foram coletados de 40 cadelas saudáveis (1-6 anos de idade), por meio de 
campanhas de castração realizadas no município de São Manuel, Estado de São Paulo, Brasil. O uso das gônadas dos animais desta pesquisa teve a aprovação do comitê de ética da Faculdade de Medicina Veterinária e Zootecnia (FMVZ-UNESP), com o número de referência 84/2015. Os ovários foram isolados assepticamente, imersos em solução fisiológica $(\mathrm{NaCl} 0,9 \%)$ e transportados a $4{ }^{\circ} \mathrm{C}$. Feito isso, foram transferidos para placa de Petri contendo tampão fosfato salina (PBS), pH 7,2 adicionado de $10 \%$ de soro fetal bovino (SFB). A identificação da fase do ciclo estral foi baseada na classificação proposta por Otoi et al. ${ }^{(16)}$ da fase de anestro (ovários com ausência de folículos ou corpo lúteo) e diestro (ovários com a presença de um ou mais corpos lúteos).

Os ovários foram seccionados com lâminas de bisturi ao longo do seu comprimento e largura para a liberação dos CCOs, identificados sob lupa estereomicroscópica (Leica ${ }^{\circledR}$ MZ 12,5) e classificados conforme a homogeneidade, coloração do citoplasma e número de camadas das células do cumulus, segundo os critérios morfológicos adotados por Hewitt e England ${ }^{(17)}$. Apenas os CCOs grau 1 foram utilizados neste estudo. Os CCOs foram lavados três vezes em meio TCM-199 suplementado com $100 \mathrm{U} / \mathrm{mL}$ de penicilina com $100 \mathrm{mg} / \mathrm{mL}$ estreptomicina, $0,2 \mathrm{mM}$ de piruvato, $20 \mathrm{mM}$ de HEPES e 5 $\mathrm{mM}$ de bicarbonato de sódio.

Os CCOs grau 1 foram submetidos à MIV em placas de cultivo de quatro poços, contendo $500 \mu \mathrm{L}$ de meio de maturação e divididos em dois grupos, denominados grupo controle (GC) e grupo tratamento (GT). No GC, os CCOs foram cultivados em meio TCM-199 acrescido de $100 \mathrm{U} / \mathrm{mL}$ de penicilina com $100 \mathrm{mg} / \mathrm{mL}$ estreptomicina, $26 \mathrm{mM}$ de bicarbonato de sódio, 1,5 $\mathrm{mM}$ de piruvato de sódio, 2,9 $\mathrm{mM}$ lactato de sódio pentahidratado, 0,6 $\mathrm{mM}$ de cisteína, $0,03 \mathrm{UI} / \mathrm{mL}$ de hCG, 0,5 $\mu \mathrm{g} / \mathrm{mL}$ de FSH, $20 \mu \mathrm{g} / \mathrm{mL}$ de $\mathrm{E}_{2}$ e $10 \eta \mathrm{g} / \mathrm{mL}$ do fator de crescimento epidermal (EGF), em estufa úmida a $38{ }^{\circ} \mathrm{C}, 5 \%$ de $\mathrm{CO}_{2}$ por um período de 72 horas. Já no GT, os CCOs foram cultivados no mesmo meio de maturação, suplementado com $25 \mathrm{mM}$ de HEPES. Após esse período de cultivo, os CCOs foram colocados em solução de hialuronidase $0,2 \%$, para a remoção das células do cumulus $e$ transferidos para solução de PBS, suplementada com paraformaldeído 3,7\%. Posteriormente, os oócitos foram lavados novamente no PBS, corados com $10 \mu \mathrm{g} / \mathrm{mL}$ de Hoechst 33342, colocados entre lâmina e lamínula, e avaliados pelo microscópio de luz e fluorescência Leica ${ }^{\circledR}$ DFC 310 FX para avaliação da maturação nuclear. Os oócitos foram classificados de acordo com a morfologia do DNA em cinco estágios: vesícula germinativa (VG), quebra de vesícula germinativa (QVG), metáfase I (M-I), metáfase II (M-II) e degenerados, ou não passíveis de identificação.

As análises estatísticas foram realizadas através do programa estatístico SAS® (Statistical Analysis System, 2009). O teste de Fisher foi empregado para avaliar a associação do meio HEPES com a maturação nuclear dos oócitos obtidos das fases de anestro e diestro. $\mathrm{O}$ grau de significância utilizado para rejeitar a hipótese de nulidade foi de $5 \%$, ou seja, foram consideradas estatisticamente significativas proporções menores que 0,05 .

\section{Resultados}

Foram isolados 456 oócitos grau 1 (246 oócitos obtidos de ovários na fase de anestro e 210 oócitos obtidos de ovários na fase de diestro), que foram caracterizados e utilizados para avaliação da maturação nuclear. Os oócitos do GT obtidos da fase de diestro demonstraram, em relação ao grupo GC, diferença altamente significativa $(\mathrm{p}<0,01)$ de oócitos nos estágios M-II (Tabela 1). 
Tabela 1. Efeito da suplementação com HEPES na maturação in vitro de oócitos caninos obtidos da fase de diestro, Botucatu, 2015

\begin{tabular}{|c|c|c|c|c|c|c|}
\hline \multirow[b]{2}{*}{ Grupos } & \multirow[b]{2}{*}{$\begin{array}{c}\mathrm{N}^{\circ}(\%) \text { de } \\
\text { oócitos }\end{array}$} & \multicolumn{5}{|c|}{ Estágios da maturação nuclear } \\
\hline & & $\begin{array}{c}\text { VG } \\
\text { n (\%) }\end{array}$ & $\begin{array}{l}\text { QVG } \\
\text { n (\%) }\end{array}$ & $\begin{array}{c}\text { M-I } \\
\text { n (\%) }\end{array}$ & $\begin{array}{c}\text { M-II } \\
\text { n (\%) } \\
\end{array}$ & $\begin{array}{l}\text { DEG } \\
\text { n (\%) }\end{array}$ \\
\hline Controle (C) & $98(100)$ & $09(9,0)^{\mathrm{a}}$ & $25(25,9)^{\mathrm{a}}$ & $16(16,9)^{\mathrm{a}}$ & $01(1,1)^{\mathrm{a}}$ & $49(47,1)^{\mathrm{a}}$ \\
\hline Tratamento $(\mathrm{T})$ & $112(100)$ & $09(7,8)^{\mathrm{a}}$ & $22(20,0)^{\mathrm{a}}$ & $21(18,9)^{\mathrm{a}}$ & $24(21,1)^{\mathrm{b}}$ & $36(31,7)^{\mathrm{a}}$ \\
\hline Total & $210(100)$ & $18(8,6)$ & $47(22,0)$ & $37(17,6)$ & $25(11,9)$ & $85(40,4)$ \\
\hline
\end{tabular}

Valores com letras iguais sobrescritas minúsculas na mesma coluna não diferem entre si estatisticamente com nível de significância 5\% pelo teste de Fisher. VG: vesícula germinativa, QVG: quebra de vesícula germinativa; M-I: metáfase-I, M-II: metáfase II, DEG: degenerados ou não passiveis de classificação.

Os oócitos do GT obtidos da fase de anestro também apresentaram, em relação ao GC, alto índice de oócitos no estágio de M-II ( $\mathrm{p}<0,05)$ (Tabela 2).

Tabela 2. Efeito da suplementação com HEPES na maturação in vitro de oócitos caninos obtidos da fase de anestro, Botucatu, 2015

Estágios da maturação nuclear

\begin{tabular}{lcccccc}
\cline { 3 - 7 } Grupos & $\mathbf{N}^{\circ}(\%)$ de & VG & QVG & M-I & M-II & DEG \\
& oócitos & $\mathbf{n}(\%)$ & n (\%) & n (\%) & n (\%) & n (\%) \\
\hline Controle (C) & $116(100)$ & $13(11,1)^{\mathrm{a}}$ & $30(25,8)^{\mathrm{a}}$ & $16(13,2)^{\mathrm{a}}$ & $05(4,7)^{\mathrm{a}}$ & $52(45,3)^{\mathrm{a}}$ \\
Tratamento (T) & $130(100)$ & $07(6,1)^{\mathrm{a}}$ & $04(3,1)^{\mathrm{b}}$ & $27(20,4)^{\mathrm{a}}$ & $15(11,2)^{\mathrm{b}}$ & $77(59,2)^{\mathrm{a}}$ \\
\hline Total & 246 & $27(11,0)$ & $25(10,1)$ & $43(17,5)$ & $22(9,0)$ & $129(52,4)$ \\
\hline
\end{tabular}

Valores com letras iguais sobrescritas minúsculas na mesma coluna não diferem entre si estatisticamente com nivel de significância 5\% pelo teste de Fisher. VG: vesícula germinativa, QVG: quebra de vesícula germinativa; M-I: metáfase-I, M-II: metáfase II, DEG: degenerados ou não passíveis de classificação.

Comparando-se os diferentes status reprodutivos, os oócitos obtidos da fase de diestro demonstraram diferença significativa $(\mathrm{p}<0,05)$ de oócitos nos estágios M-II e QVG (Tabela 3), quando comparados aos oócitos obtidos da fase de anestro.

Tabela 3. Efeito da suplementação com HEPES na maturação in vitro de oócitos caninos obtidos das fases de anestro e diestro, Botucatu, 2015

\begin{tabular}{|c|c|c|c|c|c|c|}
\hline \multirow[b]{2}{*}{ Grupos } & \multirow[b]{2}{*}{$\begin{array}{c}\mathrm{N}^{\circ}(\%) \\
\text { de oócitos }\end{array}$} & \multicolumn{5}{|c|}{ Estágios da maturação nuclear } \\
\hline & & $\begin{array}{c}\text { VG } \\
\text { n (\%) }\end{array}$ & $\begin{array}{l}\text { QVG } \\
\text { n (\%) }\end{array}$ & $\begin{array}{c}\text { M-I } \\
\text { n (\%) }\end{array}$ & $\begin{array}{c}\text { M-II } \\
\text { n (\%) }\end{array}$ & $\begin{array}{c}\text { DEG } \\
\text { n (\%) }\end{array}$ \\
\hline Diestro & $112(100)$ & $09(7,8)^{\mathrm{a}}$ & $22(20,0)^{\mathrm{a}}$ & $21(18,9)^{\mathrm{a}}$ & $24(21,1)^{a}$ & $36(31,7)^{\mathrm{a}}$ \\
\hline Anestro & $130(100)$ & $07(6,1)^{\mathrm{a}}$ & $04(3,1)^{\mathrm{b}}$ & $27(20,4)^{\mathrm{a}}$ & $15(11,2)^{b}$ & $77(59,2)^{\mathrm{a}}$ \\
\hline Total & & & & & & \\
\hline
\end{tabular}

\section{Discussão}

Diversos protocolos envolvendo a MIV vêm sendo desenvolvidos buscando a elaboração de um meio 
de cultivo ideal que simule as condições in vivo do cão doméstico e, consequentemente, que incremente as taxas de maturação nuclear. No entanto, os resultados ainda não são promissores, o que representa um entrave para o desenvolvimento de técnicas de reprodução assistida. Na tentativa de promover melhor aquisição da competência meiótica, examinamos a influência do HEPES no cultivo in vitro de oócitos caninos obtidos das fases de diestro e anestro. Esta é a primeira vez que o meio HEPES é avaliado associado à aquisição da competência meiótica de oócitos caninos e este estudo demonstrou que a utilização do HEPES potencializa os índices de M-II, independentemente da fase do ciclo estral em que o oócito é obtido, quando comparado ao meio TCM-199 sem essa suplementação.

A maioria dos estudos envolvendo a MIV no cão doméstico utiliza o meio TCM-199, modificado ou não, sob condições de temperatura e umidade variáveis ${ }^{(17)}$. O meio TCM-199, além de modificado, pode ter a adição de esteroides e outros fatores que possibilitem o desenvolvimento oocitário, como o soro fetal bovino (SFB) e a albumina sérica bovina (BSA). De acordo com Bolamba et al. ${ }^{(19)}$, o uso dessas substâncias aumenta a sobrevivência dos oócitos no meio de cultivo, já que previne alterações desfavoráveis da zona pelúcida e favorece a aderência das células do cumulus ao oócito, favorecendo, dessa forma, a progressão da maturação e, consequentemente, a fecundação.

Em cães, diversas concentrações de soro foram acrescidas ao meio TCM-199, como 10\% de soro de cadela em estro e $5 \%$ de SFB e $0,3 \%$ de BSA $^{(17)}$. Neste estudo, foi utilizada suplementação de $10 \%$ do SFB em meio TCM-199, tamponado com 25 mM de HEPES durante a seleção e lavagem dos oócitos. Em nossa rotina laboratorial observamos que, durante a classificação dos oócitos que seriam utilizados para MIV, a suplementação com o SFB no meio com HEPES promoveu melhor preservação da morfologia oocitária. Com base nessas observações, pode-se afirmar que a habilidade da competência oocitária é afetada antes mesmo do cultivo in vitro. O oócito, ao ser retirado do ambiente intrafolicular, necessita de condições in vitro que possam simular da forma mais fidedigna possível o ambiente folicular in vivo em que se encontrava. Dessa forma, é essencial a elaboração de um meio com base nas necessidades endócrinas da cadela, já que essa espécie apresenta fisiologia reprodutiva única, e que seja apropriado para as diversas etapas de manipulação, desde o transporte dos ovários, até a seleção, lavagem e maturação dos oócitos. Nesse sentido, como demonstrado no presente estudo, o HEPES é um meio benéfico na preservação dos oócitos caninos, especialmente na manipulação destes em ar atmosférico, já que esse meio associado ao bicarbonato de sódio mantém o pH em equilíbrio, contribuindo na preservação dos oócitos durante as diferentes etapas da MIV.

De acordo com Silva et al. ${ }^{(10)}$, o meio utilizado para o transporte dos óocitos é um dos fatores que mais exerce influência na produção de embriões. Segundo esses autores, o uso de meios adequados de transporte é fundamental para o posterior desenvolvimento embrionário, pois possibilita aos oócitos condições adequadas de maturação, mesmo durante o transporte, auxiliando no processo de capacitação oocitária. O HEPES é um agente tamponante que evita grandes variações de $\mathrm{pH}$ nos meios de transporte, maturação e cultivo embrionário, não sendo dependente de $\mathrm{CO}_{2}$ e, portanto, é ideal para ser utilizado no transporte e maturação de oócitos sem atmosfera gasosa ${ }^{(10)}$. Neste estudo foram demonstrados os efeitos do HEPES na MIV canina para progressão nuclear. Esse tampão também foi utilizado para a preservação de oócitos durante a seleção e observou-se que a adição do HEPES promove menor degeneração oocitária devido à capacidade de proporcionar menor variação de pH no meio. Nossa rotina laboratorial demonstrou que, no mesmo período de tempo de seleção e classificação oocitária, oócitos mantidos no meio HEPES mantinham-se viáveis a longo prazo. Um alto índice de oócitos que foram mantidos apenas no meio TCM-199 desintegraram-se na manipulação ou apresentaram alteração morfológica.

Kurtz-Filho et $a l .{ }^{(20)}$ observaram alta taxa de clivagem em embriões bovinos e esse sucesso foi 
atribuído ao uso da suplementação de $25 \mathrm{mM}$ de HEPES no meio de cultivo in vitro. Segundo esses autores, a adição desse tampão possivelmente minimizou mudanças de $\mathrm{pH}$, possibilitando maior competência na maturação e desenvolvimento embrionário. No presente estudo, foi identificado que o meio TCM-199 suplementado com HEPES proporciona melhores condições de progressão da maturação nuclear em oócitos de cadelas, sendo o HEPES essencial para a aquisição da competência meiótica destes oócitos, fato representado pelos índices de M-II, que foram observados nos oócitos coletados nas diferentes fases reprodutivas. A limitação no cultivo in vitro de oócitos caninos pode ser atribuída à adaptação de protocolos adotados in vitro com êxito para espécies como bovinos e suínos. Entretanto, eles não podem ser aplicados para cadela, já que ela apresenta particularidades em sua biologia reprodutiva que a diferencia das outras espécies domésticas. Enquanto na maioria dos mamíferos domésticos os oócitos são expostos às secreções do oviduto durante 3-4 dias, nos canídeos eles permanecem durante um longo período de tempo (8,5-9 dias), demonstrando que esse ambiente parece ser crucial para a habilidade de transição do oócito para o estágio de M-II. Assim, a adição do HEPES no meio de cultivo, evitando alterações de $\mathrm{pH}$, pode ter refletido de forma mais fidedigna o ambiente endócrino e bioquímico do oviduto, possibilitando, dessa forma, que os oócitos tornem-se mais capacitados meioticamente.

Estudos desenvolvidos em embriões humanos demonstraram que os fusos meióticos e mitóticos são estruturas sensíveis às oscilações de temperatura e $\mathrm{pH}$ durante o cultivo de gametas e embriões, podendo os microtúbulos sofrerem despolimerização diante de uma situação de estresse causada por essas oscilações e, consequentemente, resultar em embriões cromossomicamente anormais ${ }^{(22)}$. Dessa forma, a utilização do HEPES, atuando como agente tamponante que evita essas oscilações, pode ter contribuído para a correta divisão das células, potencializando os índices de oócitos aptos a completarem seu desenvolvimento meiótico. Neste estudo, observou-se nos oócitos obtidos da fase de anestro que, apesar do meio TCM-199 proporcionar alto índice de retomada da meiose (QVG) $(\mathrm{p}<0,05)$, a suplementação com o HEPES possibilitou que completassem seu desenvolvimento atingindo o estágio de M-II.

A influência do ciclo estral vem sendo associada à progressão da maturação, porém não há consenso na literatura sobre seus benefícios na capacidade de desenvolvimento oocitário. Luvoni et al. ${ }^{(6)}$ demonstraram que os oócitos advindos de animais em anestro não teriam capacidade para atingir a M-II. Em estudos prévios, Luvoni et al. ${ }^{(21)}$ reportaram que há influência do ciclo estral sobre o funcionamento das junções gap entre as células do cumulus e os oócitos. De acordo com esses autores, enquanto os CCOs advindos de cadelas em anestro apresentam as junções GAP fechadas, os CCOs provenientes de cadelas no final do proestro possuem $89 \%$ dessas comunicações abertas, podendo ser uma das causas das baixas taxas de MIV observadas na espécie canina. Hewitt e England ${ }^{(17)}$ demonstraram que não houve diferença na taxa de maturação oocitária entre oócitos coletados de cadelas nas fases de anestro e diestro. Segundo Willingham-Rocky et al. ${ }^{(23)}$, o estágio do ciclo estral da doadora é fator-chave no critério de seleção para oócitos caninos meioticamente competentes. Neste estudo demonstramos que os oócitos obtidos da fase de anestro estão aptos a alcançarem os estágios finais da maturação nuclear, como demonstrado pelos altos índices de M-II. Entretanto, comparando-se os diferentes status reprodutivos, os oócitos obtidos da fase de diestro apresentaramse mais competentes meioticamente, fato este representado pelo maior índice de oócitos nos estágios de QVG e M-II $(\mathrm{p}<0,05)$. Esses dados corroboram os resultados observados em experimentos prévios, já que as chances de se encontrar um oócito no estágio de M-II foram 1,9 $(1,04-3,46)$ vezes maiores em oócitos obtidos da fase de diestro $(\mathrm{p}<0,05)^{(4)}$. Um dos fatores responsáveis pelos oócitos obtidos da fase de diestro serem mais aptos a completarem a maturação pode ter sido pelo efeito das variações nas concentrações basais de gonadotrofinas, como ocorre em outras espécies. Essa variação já foi 
relatada em oócitos obtidos da fase de anestro e diestro nas cadelas ${ }^{(25)}$ e novos conhecimentos acerca dessas alterações precisam ser melhor elucidados.

O desenvolvimento oocitário durante a maturação in vitro, independentemente da fase do ciclo estral, é influenciada pelo $\mathrm{pH}$ mantido nas soluções. A manutenção do $\mathrm{pH}$ é preponderante para a eficiência de várias reações bioquímicas que envolvem o equilíbrio ácido-básico e se ele sofrer alterações pode causar efeitos deletérios na viabilidade celular. Dessa forma, o uso de tampões no meio de cultivo é essencial para evitar as variações de $\mathrm{pH}$ no meio, devendo permanecer entre 7,3 e 7,5 durante a maturação dos oócitos e cultivo dos embriões. Geralmente, a MIV é realizada sob atmosfera de 5\% $\mathrm{CO} 2$, com a utilização de meio tamponado com bicarbonato de sódio para a manutenção do $\mathrm{pH}$ em 7,4. O meio HEPES proporciona a manutenção do $\mathrm{pH}$ do meio de forma mais eficiente quando comparado ao uso único de bicarbonato, sendo o sistema tampão orgânico de eleição para o cultivo de tecidos e células animais. O HEPES, quando utilizado por curto período de tempo, se mostra vantajoso. Entretanto, estudos demonstraram que o HEPES pode diminuir o $\mathrm{pH}$ intracelular ou causar uma diferença na incorporação de substratos carbono no RNA e/ou DNA, resultando, dessa forma, na alteração no desenvolvimento da competência dos oócitos preservados ${ }^{(26)}$. Com base nisso, podese observar que os resultados da utilização do HEPES podem variar de acordo com a espécie estudada, o que demonstra necessidades diferentes que dependem da fisiologia reprodutiva de cada animal. No caso dos canídeos, esse meio pode ser considerado uma alternativa eficaz para potencializar o índice de retomada da meiose, já que parcela significativa desses oócitos permanece no estágio de vesícula germinativa mesmo após dias de cultivo.

Em conclusão, nossos dados sugerem que a adição do HEPES conseguiu preservar a viabilidade e morfologia oocitária, indispensáveis para a aquisição da competência meiótica, incrementando as taxas de M-II na espécie canina.

\section{Agradecimentos}

À Fundação de Apoio à Pesquisa do Estado de São Paulo pelo suporte financeiro FAPESP 2013/21667-3, 2014/19776-1.

\section{Referências}

1. Byskov AG, Yding-Andersen C, Hossaini A, Guoliang X. Cumulus cells of oocyte-cumulus complexes secrete a meiosis activating substance when stimulated with FSH. Mol Reprod Dev [Internet].1997 [citado 2018 Maio 09]; 46:296-305. Disponível em: http://dx.doi.org/10.1002/(SICI)10982795(199703)46:3<296::AID-MRD8>3.0.CO;2-K.

2. Farstad W. Assisted reproductive technology in canid species. Theriogenology [Internet]. 2000 [citado 2018 Maio 09]; 52:175-186. Disponível em: https://doi.org/10.1016/S0093-691X(99)00250-2

3. Pereira LMC.; Bersano PRO, Lopes MD. Efeito do fator de crescimento epidermal (EGF) na maturação in vitro de oócitos caninos. Braz. J. Vet. Res. Anim. Sci Science [Internet]. 2014 [citado 2018 Maio 09]; 51:158165. Disponível em: https://doi.org/10.11606/issn.1678-4456.v51i2p158-165

4. Pereira LMC.; Bersano PRO, Lopes MD. Influência das fases de anestro e diestro na competência oocitária de cadelas. Braz. J. Vet. Res. Anim. Sci Science [Internet]. 2015 [citado 2018 Maio 09]; 52: 266-272. Disponível em: https://doi.org/10.11606/issn.1678-4456.v52i3p266-272

5. Fujihara M, Comizzoli P, Wildt DE, Songsasen N. Cat and dog primordial follicles enclosed in ovarian 
cortex sustain viability after in vitro culture on agarose gel in a protein-free medium. Reprod Domest Anim [Internet]. 2012 [citado 2018 Maio 09]; 47:102-108. Disponível em: https://doi.org/10.1111/rda.12022

6. Luvoni GC, Chigioni S, Allievi E, Macis D. Factors involved in vivo and in vitro maturation of canine oocytes. Theriogenology [Internet]. 2005 [citado 2018 Maio 09]; 63: 41-59. Disponível em: https://doi.org/10.1016/j.theriogenology.2004.03.004

7. Machado MA, Toniollo GH, Oliveira K. Influência do fator de crescimento semelhante à insulina I (IGF-I) adicionado ao meio fluido sintético de tuba uterina (SOF) sobre a maturação in vitro de oócitos caninos (Canis familiaris). Semina: Ciênc. Agrár [Internet]. 2007 [citado 2018 Maio 09]; 28: 455-464. Disponível em: http://www.redalyc.org/articulo.oa?id=445744085010.

8. Song HJ, Kang EJ, Maeng GH, Ock SA, Lee SL, Yoo JG, Jeon BG, Rho GJ. Influence of epidermal growth factor supplementation during in vitro maturation on nuclear status and gene expression of canine oocytes. Res Vet Sci [Internet]. 2011[citado 2018 Maio 09]; 94: 439-445. Disponível em: https://doi.org/10.1016/j.rvsc.2010.09.003.

9. Silva C, Calegari RA, Martins JR A. Desenvolvimento de embriões bovinos após maturação in vitro de oócitos em meio de cultivo suplementado com taurina ou glicina. Veterinária e Zootecnia [Internet]. 2009 [citado 2018 Maio 09]; 16: 89-100. Disponível em: http://www.fmvz.unesp.br/rvz/index.php/rvz/article/view/393

10. Silva LKX, Reis NA, Silva AOA, Sousa JS, Souza AJO, Vale WG. Transporte de oócitos bovinos em meio de maturação por diferentes períodos de tempo sem controle da atmosfera gasosa. Arq Bras Med Vet Zootec [Internet]. 2011 [citado 2018 Maio 09]; 63: 74-80. Disponível em: http://www.scielo.br/pdf/abmvz/v63n1/v63n1a12.pdf

11. Evecen M, Cirit U, Demir K, Ozdas OB, Taz M, Birler S, Pabuccuoglu S. Effects of estrous cycle stage and transport temperature of ovaries on in vitro maturation of canine oocytes. Animal Reproduction Science [Internet]. 2010 [citado 2018 Maio 09]; 117:160-165. Disponível em: http://www.scielo.br/pdf/cr/v34n1/a34v34n1.pdf

12. Goto K, Iwai N, Takuma Y, Nakanishi Y. Co-culture of in vitro fertilized bovine embryos with different cell monolayers. J Anim Sci [Internet]. 1992 [citado 2018 Maio 09]; 70:1449-53. Disponível em: https://doi.org/10.2527/1992.7051449x

13. Liu Z, Foote RH, Simkim ME. Effect of aminoacids and alpha-amanitin on the development of rabbit embryos in modified protein-free KSOM with HEPES. Mol Reprod Dev [Internet]. 1996 [citado 2018 Maio 09]; 45: 157-162. Disponível em: https://doi.org/10.1002/(SICI)1098-2795(199610)45:2<157::AIDMRD8>3.0.CO;2-S.

14. Pollard JW, Plante C, Leibo SP. Comparison of development of pig zygotes and embryos in simple and complex culture media. J Reprod Fertil [Internet]. 1995 [citado 2018 Maio 09]; 103: 331-7. Disponível em: http://www.reproduction-online.org/content/103/2/331.full.pdf.

15. Vatja G, Holm P, Greve T, Callesen H. Effect of $\mathrm{pH}$ of culture medium on in vitro development of bovine embryos. Theriogenology [Internet]. 1997 [citado 2018 Maio 09]; 47: 286. Disponível em: https://doi.org/10.1016/S0093-691X(97)82413-2.

16. Otoi T, Willingham L, Shin T, Kraemer DC, Westhusin M. Effects of oocyte culture density on meiotic competence of canine oocytes. Reproduction [Internet]. 2002 [citado 2018 Maio 09]; 124: 775-781. Disponível em: https://doi.org/10.1530/reprod/124.6.775.

17. Hewitt DA, England GCW. The effect of preovulatory endocrine events upon maturation of oocytes of domestic bitch. J Reprod Fertil [Internet]. 1997 [citado 2018 Maio 09]; 51:83-91. https://www.ncbi.nlm.nih.gov/pubmed/9404274

18. SAS Institute. 2009. SASSTAT User's Guide. Version 9.2, SAS Institute Inc., Cary, NC. 
19. Bolamba D, Borden-Russ KD, Durrant BS. In vitro maturation of bitch oocytes from advanced preantral follicles in synthetic oviduct fluid medium: serum is not essencial. Theriogenology [Internet]. 2002 [citado 2018 Maio 09]; 581: 1689-1703. Disponível em: https://doi.org/10.1016/S0093-691X(02)01080-4.

20. Kurtz Filho M, Silva LM, Moreira B, Brum DS, Leivas FG, Silva CAM, Rubin MIB. Maturação e fecundação in vitro de oócitos bovinos em tubos previamente gaseificados e mantidos em banho-maria. Archives of Veterinary Science [Internet]. 2002 [citado 2018 Maio 09]; 7: 121-127. Disponível em https://dx.doi.org/10.5380/avs.v7i2.3991.

21. Luvoni GC, Luciano AM, Modina S, Gandolfi F. Influence of different stages of the oestrous cycle on cumulus-oocyte communications in canine oocytes: effects on the efficiency of in vitro maturation. J Reprod Fertil Suppl [Internet]. 2001 [citado 2018 Maio 09]; 57:141-146. https://www.ncbi.nlm.nih.gov/pubmed/11787141

22. Pickering SJ, Taylor A, Johnson MH, Braude PR. An analysis of multinucleated blastomere formation in human embryos. Hum Reprod [Internet]. 1995 [citado 2019 Maio 01];10(7):1912-22. Disponível em: https://doi.org/10.1093/molehr/1.5.254

23. Willingham-Rocky LA, Hinrichs K, Westhusin ME, Kraemer DC. Effects of stage of oestrus cycle and progesterone supplementation during culture on maturation of canine oocytes in vitro. Reproduction [Internet]. 2003 [citado 2018 Maio 09]; 126:501-508. Disponível em: https://doi.org/10.1530/reprod/126.4.501

24. Gottardi FP, Mingoti GZ. Maturação de oócitos bovinos e influência na aquisição da competência para o desenvolvimento do embrião. Ver Bras Reprod Anim [Internet]. 2009 [citado 2019 Maio 01]; 33: 82-94. Disponível em: http://www.cbra.org.br/pages/publicacoes/rbra/download/pag82-94.pdf

25. Kooistra HS, Okkens AC, Bevers MM, Popp-Snijders C, Van Haaften B, Dieleman SJ, Schoemaker J. Concurrent pulsatile secretion of luteinizing hormone and follicle-stimulating hormone during different phases of the estrous cycle and anestrus in beagle bitches. Biology of Reproduction [Internet]. 1999 [citado 2018 Maio 24]; 60, 65-71. Disponível em: https://doi.org/10.1095/biolreprod60.1.65.

26. Hashimoto S, Minami N, Takakura R, Imai H. Bovine immature oocytes acquire developmental competence during meiotic arrest in vitro. Biol Reprod [Internet]. 2002 [citado 2019 Maio 01]; 66: 1696-1701. Disponível em: https://doi.org/10.1095/biolreprod66.6.1696 